\title{
Soluble proteins of chemical communication: an overview across arthropods
}

\author{
Paolo Pelosi ${ }^{1}$, Immacolata lovinella ${ }^{2}$, Antonio Felicioli ${ }^{3}$ and Francesca R. Dani ${ }^{2,4}{ }^{*}$ \\ 1 State Key Laboratory for Biology of Plant Diseases and Insect Pests, Institute of Plant Protection, Chinese Academy of Agricultural Sciences, Beijing, China \\ ${ }^{2}$ Biology Department, University of Firenze, Firenze, Italy \\ ${ }^{3}$ Department of Veterinary Sciences, University of Pisa, Pisa, Italy \\ ${ }^{4}$ CISM, Mass Spectrometry Centre, University of Firenze, Firenze, Italy
}

\section{Edited by:}

Raman Chandrasekar, Kansas State University, USA

\section{Reviewed by:}

Raman Chandrasekar, Kansas State University, USA

Murugan E. Kadarkarai, Bharathiar

University, India

${ }^{*}$ Correspondence:

Paolo Pelosi, State Key Laboratory for Biology of Plant Diseases and Insect Pests, Institute of Plant Protection, Chinese Academy of Agricultural Sciences, 2, West Yuanmingyuan Rd., Haidian District, Beijing 100193, China

e-mail:ppelosi.obp@gmail.com; Francesca R. Dani, Department of Biology, University of Firenze, Via Madonna del Piano, 6, 50019 Sesto Fiorentino, Italy

e-mail: francescaromana.dani@ unifi.it
Detection of chemical signals both in insects and in vertebrates is mediated by soluble proteins, highly concentrated in olfactory organs, which bind semiochemicals and activate, with still largely unknown mechanisms, specific chemoreceptors. The same proteins are often found in structures where pheromones are synthesized and released, where they likely perform a second role in solubilizing and delivering chemical messengers in the environment. A single class of soluble polypeptides, called Odorant-Binding Proteins (OBPs) is known in vertebrates, while two have been identified in insects, OBPs and CSPs (Chemosensory Proteins). Despite their common name, OBPs of vertebrates bear no structural similarity with those of insects. We observed that in arthropods OBPs are strictly limited to insects, while a few members of the CSP family have been found in crustacean and other arthropods, where however, based on their very limited numbers, a function in chemical communication seems unlikely. The question we address in this review is whether another class of soluble proteins may have been adopted by other arthropods to perform the role of OBPs and CSPs in insects. We propose that lipid-transporter proteins of the Niemann-Pick type C2 family could represent likely candidates and report the results of an analysis of their sequences in representative species of different arthropods.

Keywords: odorant-binding proteins, chemosensory proteins, Niemann-Pick type C2 proteins, Insect olfaction, basal hexapods, arthropod chemoreception

\section{SOLUBLE BINDING PROTEINS IN DETECTION AND DELIVERY OF SEMIOCHEMICALS}

Odor detection is accomplished in vertebrates as in insects through a complex and sophisticated sensory system making use of both membrane-bound receptors (Buck and Axel, 1991; Clyne et al., 1999; Vosshall et al., 1999) and soluble binding proteins (Pelosi et al., 1981, 1982; Vogt and Riddiford, 1981). These latter are commonly regarded as solubilizers and carriers of odorants and pheromones, generally hydrophobic compounds, but in recent times evidence has been provided in some insect species for more specific and important roles. In particular, knockout experiments have demonstrated that an OBP of Drosophila melanogaster, LUSH, is required for olfaction (Xu et al., 2005; Laughlin et al., 2008), while behavior assays with Drosophila mutants (Matsuo et al., 2007; Swarup et al., 2011) and with aphids (Qiao et al., 2009; Sun et al., 2012a) have indicated that OBPs are involved in semiochemical discrimination.

Odorant-binding proteins (OBPs) is the name designating two structurally unrelated families of polypeptides abundantly secreted into the nasal mucus of vertebrates and in the lymph of chemosensilla in insects. OBPs of vertebrates contain 150160 amino acids (Bignetti et al., 1985; Pevsner et al., 1985; Pelosi, 1994, 1996; Tegoni et al., 2000) and belong to the superfamily of lipocalins (Flower, 1996, 2000), carrier proteins folded in the typical $\beta$-barrel shape, with eight $\beta$-sheets and one short segment of $\alpha$-helix close to the C-terminus (Bianchet et al., 1996; Tegoni et al., 1996). OBPs of insects (around 130-140 residues), instead (Vogt and Riddiford, 1981; Pelosi et al., 2006; Vieira and Rozas, 2011; Leal, 2013), are made of six $\alpha$-helical domains assembled in a compact and stable structure (Sandler et al., 2000; Tegoni et al., 2004). They are characterized by a pattern of six conserved cysteines paired into three interlocked disulfide bridges (Leal et al., 1999; Scaloni et al., 1999).

A third class of soluble binding proteins, named Chemosensory Proteins (CSPs) is also found in olfactory and gustatory organs of insects (McKenna et al., 1994; Pikielny et al., 1994; Angeli et al., 1999; Wanner et al., 2004; Pelosi et al., 2006; Vieira and Rozas, 2011). CSPs are around 100-120 residues long and present a conserved pattern of four cysteines forming two independent loops (Angeli et al., 1999). CSPs are also made of $\alpha$-helical segments, but assembled in a folding different from that of insect OBPs (Lartigue et al., 2002; Tomaselli et al., 2006; Jansen et al., 2007).

All three classes of soluble proteins contain hydrophobic binding pockets and, despite their structural differences, are believed to perform similar roles in vertebrates and in insects (Pelosi and Maida, 1990; Calvello et al., 2003). Figure 1 reports the 


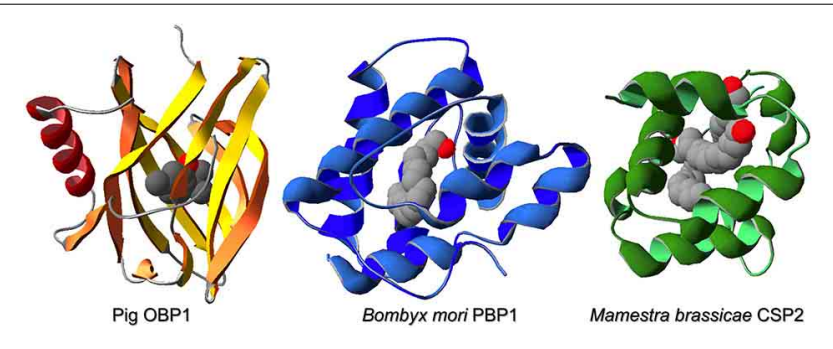

FIGURE 1 | Three-dimensional structures of pig OBP (PDB: 1E06, Vincent et al., 2000), Bombyx mori PBP1 (PDB: 1DQE, Sandler et al., 2000), and Mamestra brassicae CSP2 (PDB: 1N8U, Campanacci et al., 2003), representative examples of a vertebrate OBP, an insect OBP and an insect CSP, respectively. Proteins of these three classes, despite marked structural differences, perform similar roles of transport and solubilization of semiochemicals and are extremely compact and stable. Structures have been visualized using the Swiss-Model PDB Viewer (Guex and Peitsch, 1997).

three-dimensional folding of a representative protein from each of the three classes.

All three families of proteins, although generally associated with chemodetection, include members expressed outside chemosensory organs.

In vertebrates this phenomenon appeared clear soon after the discovery of the first OBP. In fact, it had already been known for long time that mice and rats excrete small proteins into their urine at concentrations of few milligrams per milliliter (Dinh et al., 1965; Finlayson et al., 1965), but a reasonable explanation for this large waste of energy was not proposed until sequence information was obtained for the bovine OBP, the first to be discovered, which showed high similarity with urinary proteins (Cavaggioni et al., 1987; Cavaggioni and Mucignat-Caretta, 2000). Some proteins were found both in the nasal mucosa of the mouse and in the urine, with the only difference that when secreted into urine they were loaded with species-specific pheromones (Bacchini et al., 1992; Robertson et al., 1993). More examples of mammalian OBPs involved in semiochemical delivery are the boar salivary lipocalins (Marchese et al., 1998; Loebel et al., 2000; Spinelli et al., 2002), the hamster aphrodisin (Singer et al., 1986; Vincent et al., 2001) and the horse sweat lipocalin Equ-c1 (D'Innocenzo et al., 2006). In addition, a lipocalin related to OBPs, the apolipoprotein D, was reported in human sweat, complexed with a volatile fatty acid (Zeng et al., 1996). In all these cases OBPs have been found complexed with pheromones, strongly supporting a function in semiochemical delivery. While it is reasonable to assume that the same or similar proteins might be involved in the dual role of detecting and releasing chemical signals, functions unrelated to chemical communication would appear less obvious. However, if we consider the phenomenon under a wider perspective, we realize that the superfamily of lipocalins, to which vertebrate OBPs belong, includes many different members endowed with diverse functions. In fact, all lipocalins, despite major differences in amino acid sequences, share a conserved architecture (Flower, 1996; Flower et al., 2000). The reason for such versatility of lipocalins is to be found in their extremely stable and compact structure, which allowed adaptation to various uses in different and often challenging conditions.

In insects, a similar phenomenon has only been described in recent years, but several pieces of evidence have been rapidly accumulating in different species. Both OBPs and CSPs have been detected in pheromone glands or in reproductive organs, where they might assist releasing of semiochemicals into the environment. Typical examples are the CSPs found in the pheromone glands of Mamestra brassicae (Jacquin-Joly et al., 2001), Bombyx mori (Dani et al., 2011) and Agrotis ipsilon (Gu et al., 2013), as well as the OBP10 of Helicoverpa armigera and H. assulta (Sun et al., 2012b), the OBP22 of Aedes aegypti (Li et al., 2008) and the CSP91 of Locusta migratoria, produced in the male seminal fluid and transferred to the female, likely with a bound pheromone, during mating (Ban et al., 2013; Zhou et al., 2013). Several OBPs and CSPs are also expressed in the mandibular glands of the honey bee (Iovinella et al., 2011). Other members of both classes seem to be involved in roles completely different from chemical communication. It is noteworthy that the first member of the CSP family, named p10, was discovered in a context not related to chemical communication, as a protein involved in limb regeneration in the cockroach (Nomura et al., 1992; Kitabayashi et al., 1998). Other representative examples of CSPs performing roles unrelated to chemical communication are the CSP5 of the honeybee, only found in ovaries and eggs and required for development of the embryo (Maleszka et al., 2007), and the CSP4 of Helicoverpa armigera and $H$. assulta, present in high concentration in the lumen of the proboscis and likely acting as a surfactant to help sucking (Liu et al., 2014a). Recently, CSPs have been also indicated as possible scavengers for insecticides, thus providing insects with a sort of resistance to their lethal effects (Liu et al., 2014b; Xuan et al., 2014). Some OBPs have also been related to roles other than chemoreception: OBP56a is expressed in the oral disk of the house fly Phormia regina and has been reported as a fatty acid solubilizer (Ishida et al., 2013). Other examples are two "tandem OBPs" (resulting from two different OBPs joined by a bridge of few amino acids) of the mosquito Aedes aegypti. The first is the salivary protein D7r4, which is involved in antiinflammatory processes (Calvo et al., 2009), the second is the OBP45, reported in the ovaries and eggs with a putative function in reproductive mechanisms responsible for oocyte maturation (Costa-da-Silva et al., 2013; Marinotti et al., 2014).

Figure 2 lists representative cases of OBPs (both in vertebrates and in insects) and CSPs utilized for tasks other than chemodetection.

As observed with lipocalins, compact folding and stability are the characteristics on the basis of such diverse uses of insects OBPs and CSPs, resulting in extreme refractivity to heat, chemicals and proteolytic enzymes (Paolini et al., 1999; Ban et al., 2002; Schwaighofer et al., 2014). Besides, they all present hydrophobic pockets for small and medium size organic chemicals. Therefore, it is reasonable to think that such stable and efficient binding proteins have been utilized for different tasks in various organs, wherever there was need to transport hydrophobic chemicals in aqueous media or to protect some compounds from degradation or else to assure a gradual release of semiochemicals in the environment. 


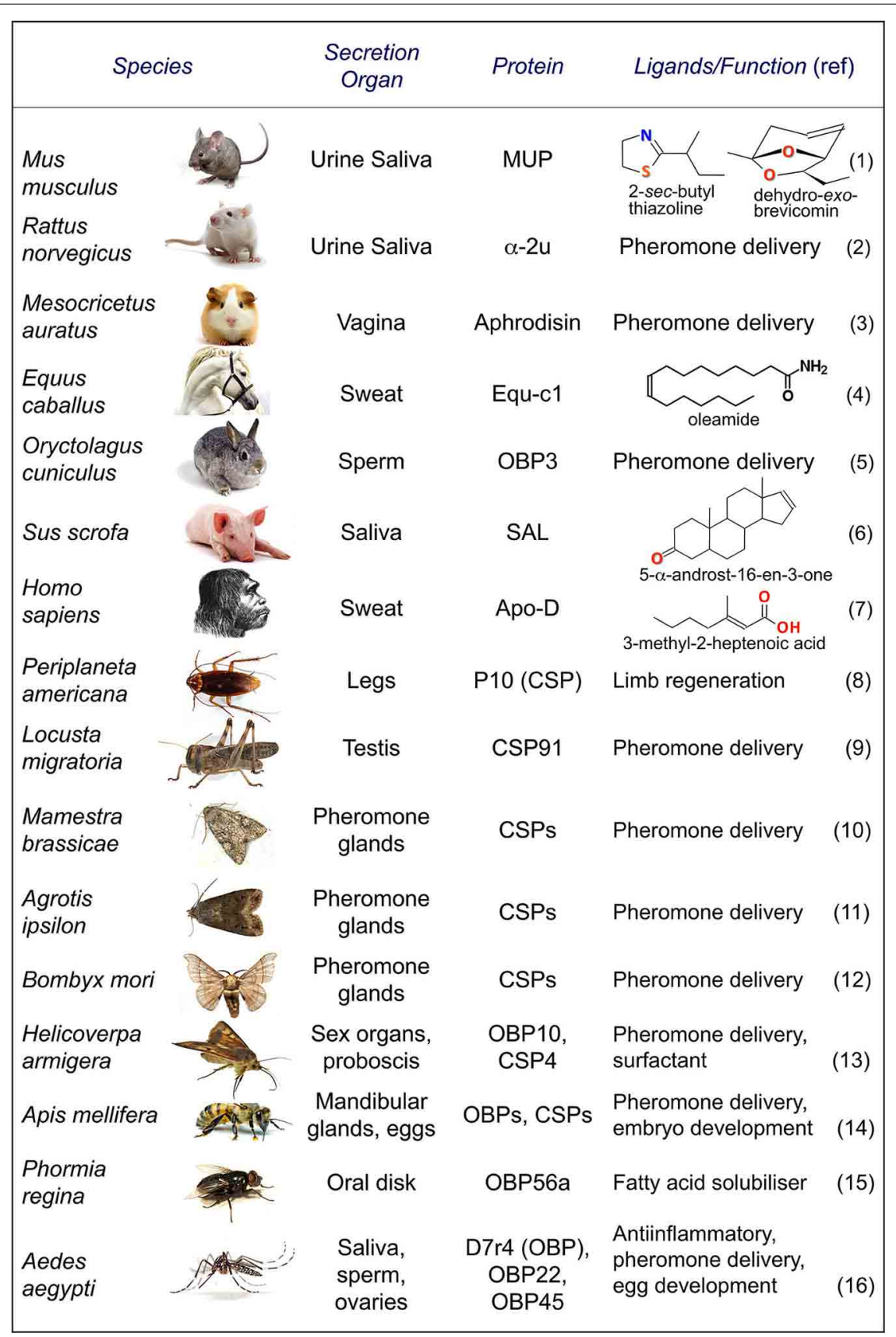

FIGURE 2 | OBPs and CSPs involved in non-sensory functions. Mammalian OBPs have been found in secretions involved in the delivery of semiochemicals. In several cases, when isolated from such biological fluids, OBPs carry species-specific pheromones. Insect OBPs and CSPs have been reported both in pheromone glands and in reproductive organs, where they likely solubilize and bind specific pheromones. Moreover, members of both classes have been reported in other tissues and shown to be involved in functions unrelated to chemical communication. (1)
Finlayson et al., 1965; Bacchini et al., 1992; (2) Dinh et al., 1965; (3) Singer et al., 1986; (4) D'Innocenzo et al., 2006; (5) Mastrogiacomo et al., 2014; (6) Marchese et al., 1998; (7) Zeng et al., 1996; (8) Nomura et al., 1992; Kitabayashi et al., 1998; (9) Zhou et al., 2013; (10) Jacquin-Joly et al., 2001; (11) Gu et al., 2013; (12) Dani et al., 2011; (13) Sun et al., 2012b; Liu et al., 2014a; (14) Iovinella et al., 2011; Maleszka et al., 2007; (15) Ishida et al., 2013; (16) Calvo et al., 2009; Costa-da-Silva et al., 2013; Marinotti et al., 2014; Li et al., 2008.
Although such high versatility is associated with all three classes of binding proteins, we can suggest that the structure of insect OBPs is probably the least adaptable to perform different functions, based on the low number of insect
OBPs so far reported to perform non-chemosensory functions, with respect to CSPs and vertebrate OBPs. In fact, the folding of insect OBPs is strongly constrained by its three interlocked disulfide bridges, as opposed to more flexible CSPs, 
which possess two separate bridges, and to vertebrate OBPs, whose $\beta$-barrel can swell to a relatively large extent, thus offering diverse structural solutions within a similar folding motif.

An important consequence of this phenomenon for discussing the data that will be presented further on is that sequence similarity alone or the assignment of a new member to one of the three families of binding proteins does not necessarily imply an involvement in chemosensing or in chemical communication.
This review focuses on soluble olfactory proteins of insects with a broader view across all arthropods, in the attempt to outline their possible evolution.

\section{OBPs AND CSPs ACROSS EVOLUTION OF INSECTS AND ARTHROPODS}

Given the structural differences between vertebrate OBPs, insects OBPs and CSPs, it is clear that these three families of proteins followed independent evolutionary paths. In particular, it would be of interest to trace down the onset of insect

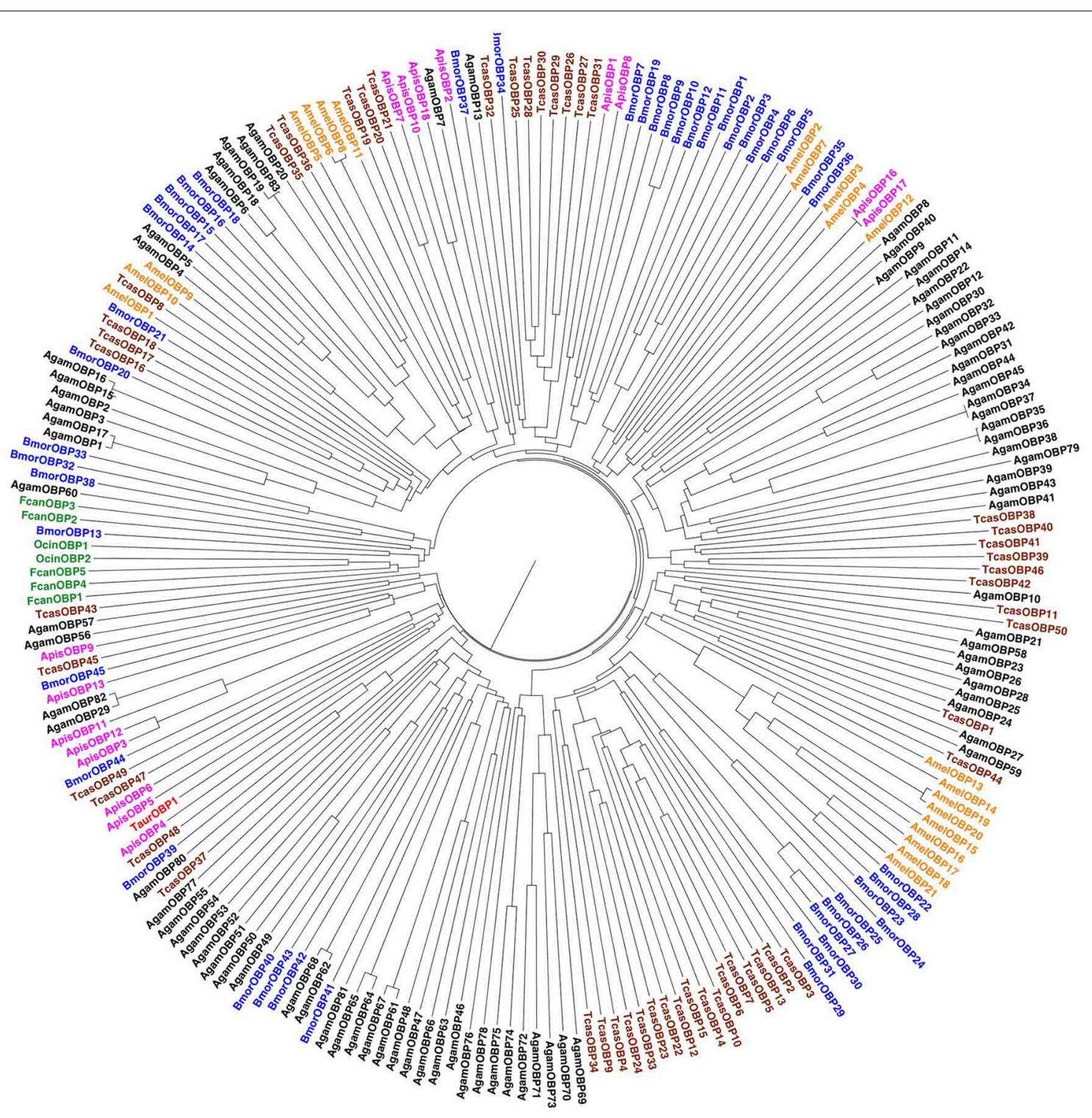

FIGURE 3 | Phylogenetic tree of OBPs from selected species of insects and basal hexapods. Among arthropods, OBPs were only found in Hexapoda. Species and color codes are as follows. Red: Zygentoma (Taur: Thricolepisma aurea); green: Collembola (Fcan: Folsomia candida; Ocin: Orchesella cincta); magenta: Hemiptera (Apis: Acyrthosiphon pisum); brown: Coleoptera (Tcas: Tribolium castaneum); blue: Lepidoptera (Bmor: Bombyx mori); orange: Hymenoptera (Amel: Apis mellifera); black: Diptera (Agam:
Anopheles gambiae). Sequences were aligned with the on-line software Clustal-W, using the following parameters. For Pairwise alignment: Protein Weight Matrix: Gonnet; Gap open: 10; Gap extension: 0.1. For Multiple sequence alignment: Protein Weight Matrix: Gonnet; Gap open: 10; Gap extension: 0.2; Gap distance: 5; Clustering: NJ. Phylogenetic trees were visualized with the software Fig Tree (http://tree.bio.ed.ac.uk/software/ figtree/). Accession numbers are taken from Vieira and Rozas, 2011. 
OBPs and CSPs and possibly identify their likely progenitor genes.

So far, insect OBPs have only been described in insects, while some CSPs have been reported in other arthropods (Forêt et al., 2007; Iovinella et al., 2013), although their involvement in chemical communication in non-insect species has not been demonstrated.

Therefore, we have searched for members of these two classes of proteins in basal hexapods (Giribet et al., 2004) and in other arthropods. For those species whose genome has been sequenced we are in the condition of stating whether or not OBPs and CSPs exist and to report the number of their genes. For other species, our search was performed by blasting the EST database using as queries the sequences of species phylogenetically (Giribet and Edgecombe, 2012) as close as possible to those under investigation.

\section{ODORANT-BINDING PROTEINS IN INSECTS AND ARTHROPODS}

OBPs have been reported in a large number and variety of insect species (Vieira and Rozas, 2011). The number of their

Table 1 | List of species examined in this work with the number of OBPs, CSPs, and NPC2s so far detected in the databases.

\begin{tabular}{|c|c|c|c|c|c|}
\hline Taxon & Order & Species & OBP & $\operatorname{CSP}$ & NPC2 \\
\hline \multicolumn{6}{|l|}{ TARDIGRADA } \\
\hline & & Hypsibius dujardini & - & - & 4 \\
\hline & & Peripatopsis sedgwicki & - & - & 1 \\
\hline & & Epiperipatus sp. & - & - & 1 \\
\hline & Tetrapulmonata, Araneae & Latrodectus hesperus & - & - & 1 \\
\hline & & Loxosceles laeta & - & - & 1 \\
\hline & Scorpiones & Hottentotta judaicus & - & - & 1 \\
\hline & Acari & Ixodes scapularis & - & 1 & 14 \\
\hline \multicolumn{6}{|l|}{ MYRIAPODA } \\
\hline & Diplopoda & Julida sp. & - & 2 & - \\
\hline & & Daphnia pulex & & 1 & 12 \\
\hline & & Triops cancriformis & - & 2 & 3 \\
\hline \multicolumn{6}{|l|}{ HEXAPODA } \\
\hline \multirow[t]{7}{*}{ Entognatha } & Diplura & Campodea fragilis & - & - & 3 \\
\hline & Protura & Acerentomon franzi & - & - & 2 \\
\hline & Collembola & Folsomia candida & 4 & 1 & 4 \\
\hline & & Anurida maritima & - & 1 & 6 \\
\hline & & Onychiurus arcticus & - & - & 11 \\
\hline & & Cryptopygus antarcticus & - & 2 & - \\
\hline & & Orchesella cincta & 2 & - & - \\
\hline & & Megachile rotundata & 7 & 7 & 4 \\
\hline & & Nasonia vitripennis & 90 & 10 & 5 \\
\hline & Diptera & Drosophila melanogaster & 52 & 4 & 7 \\
\hline & & Culex quinquefasciatus & 109 & 27 & 13 \\
\hline & & Anopheles gambiae & 69 & 8 & 6 \\
\hline
\end{tabular}

In species where the genome has been published, these figures can be considered as more or less final, in other species their numbers could increase as more information will become available. We have adopted the classification reported in Figure 5 of Giribet and Edgecombe (2012), who suggest that Mandibulata include Myriapoda, Crustacea, and Hexapoda. 
genes in species that had their genome sequenced ranges from a dozen in some ant species (Smith et al., 2011) to more than hundred in some mosquitoes (Manoharan et al., 2013). OBPs are extremely divergent in their sequences and identical amino acids between members of the same species, as well as between species, may be even lower than $10 \%$. The correct assignment of a sequence to the family of OBPs is mainly based on the conserved pattern of six cysteines, determining with their three interlocked bridges the folding and the stability of these proteins. However, OBPs with four cysteines (Cminus OBPs) or with a larger number of such residues (C-plus OBPs) have been reported in many species (Zhou et al., 2004). Based on such criteria and data, the assignment of a new protein to the class of OBPs can be performed with reasonable confidence.

Therefore, using BLAST search tools, we have looked for the presence of OBPs in basal hexapods and in other arthropods. In particular, we have searched protein databases, nucleotide collections and EST sequences in the following groups: Collembola, Diplura, Protura, Archaeognatha, and Zygentoma.

Our search only produced a total of 7 sequences in two species of Collembola, and a single sequence in a Zygentoma species, while we could not detect any gene similar to OBPs in the other groups.

A similar search could not yield any sequence recognizable as OBP in other arthropods, namely Crustacea, Myriapoda, and Chelicerata, as well as in the sister groups Onychophora and Tardigrada. In particular, we used as templates the OBPs of Locusta migratoria, Acyrthosiphon pisum, Bombyx mori, as well as those found in basal hexapods as part of this work. As for some of the species under analysis, such as Daphnia pulex, Ixodes scapularis, and Varroa destructor, partial or complete genome information is available, we can reasonably assume that the class of proteins defined as "insect OBPs" is only found in hexapods. The

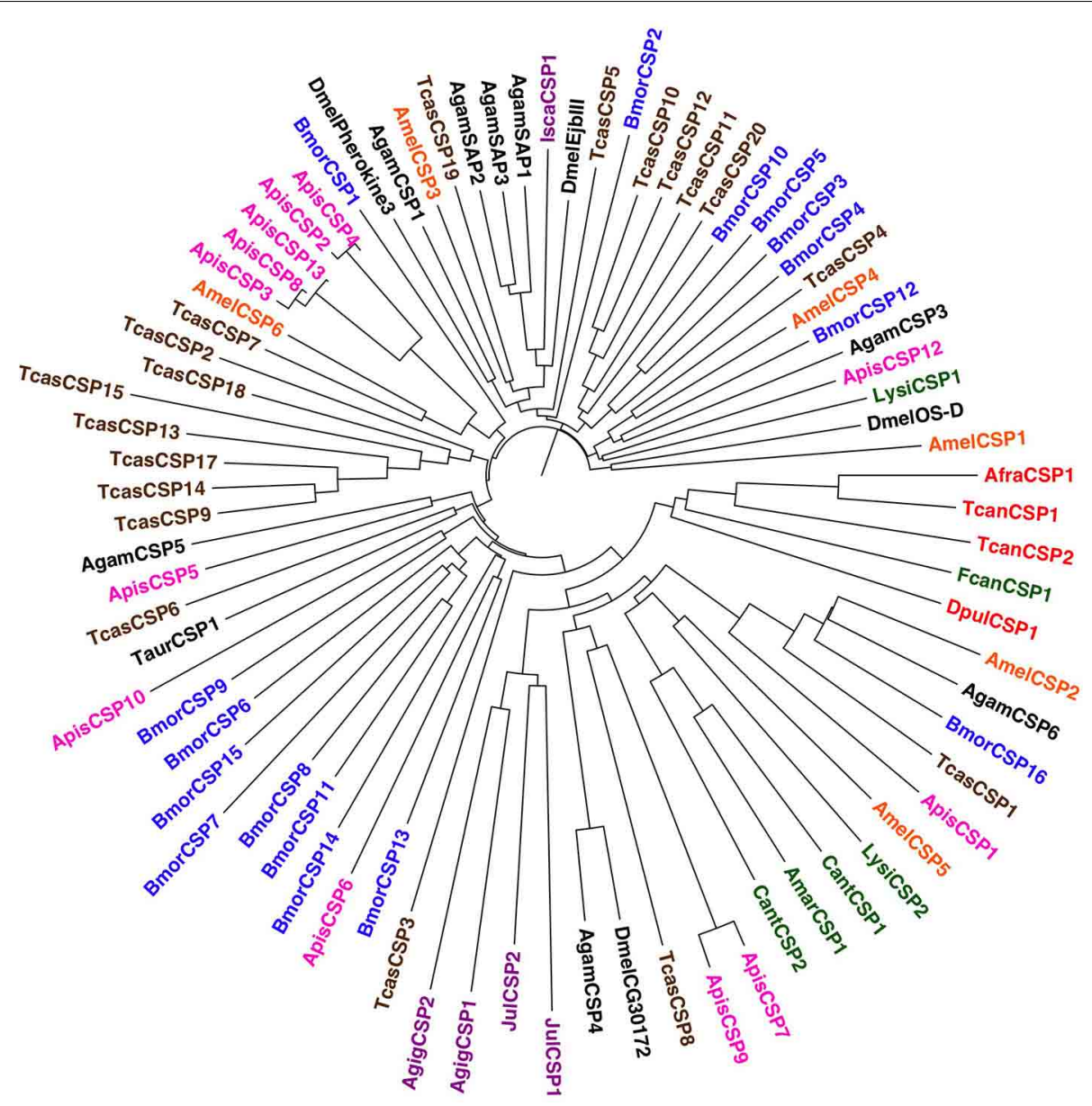

FIGURE 4 | Phylogenetic tree of CSPs from selected species of insects and other arthropods. Apart from Hexapoda, members of the CSP family have also been found in species of Euchelicerata, Myriapoda, and Crustacea. Species and color codes are as follows. Violet: Euchelicerata (Isca: Ixodes scapularis) and Myriapoda (Jul: Julida sp.; Agig: Archispirostrepsus gigas); red: Crustacea (Afra: Artemia franciscana; Dpul: Daphnia pulex; Tcan: Triops cancriformis); green: Collembola (Fcan: Folsomia candida; Amar: Anurida maritima; Cant: Cryptopygus antarcticus;
Ocin: Orchesella cincta), Archaeognatha (Lysi: Lepismachilis y-signata) and Zygentoma (Taur: Thricolepisma aurea); magenta: Hemiptera (Apis: Acyrthosiphon pisum); brown: Coleoptera (Tcas: Tribolium castaneum); blue: Lepidoptera (Bmor: Bombyx mori); orange: Hymenoptera (Amel: Apis mellifera); black: Diptera (Dmel: Drosophila melanogaster, Agam:

Anopheles gambiae). Sequences were aligned and trees were visualized as in Figure 2. Accession numbers are taken from Vieira and Rozas (2011) or are reported in Table S1. 
few OBP genes detected in basal hexapods, such as Collembola and Zygentoma, indicate that OBPs are present since the very first differentiation of the Hexapoda. How these more efficient proteins originated is still unknown, as we were not able to find sequences that might appear as progenitors in other species of arthropods.

Figure 3 reports a phylogenetic tree built with all the OBPs of selected insect species among those whose genome is available, together with the few members found in Collembola and Zygentoma. More information on the number of OBPs in each species can be found in Table 1. Although the sample of sequences relative to basal hexapods is too small to allow any conclusion, nevertheless we can observe that the five sequences of the collembolan Folsomia candida exhibit a wide divergence, as is the case with other insects OBPs, indicating that their differences can possibly cope with the diversity of semiochemicals in the environment.

\section{CHEMOSENSORY PROTEINS IN INSECTS AND ARTHROPODS}

Chemosensory proteins are better conserved than OBPs across insect species and can be found in several other arthropods, including Crustacea, Myriapoda, and Euchelicerata. With respect to OBPs, CSPs are in general more widely expressed in different parts of the body, suggestive often of nonspecific functions. As already observed for OBPs, also the number of CSP genes in different species of insects is highly variable, from as few as four in D. melanogaster (Vieira and Rozas, 2011) to at least 70 in L. migratoria (Zhou et al., 2013). Although proteins of both classes, owing to their successful folding and stability, are utilized for different tasks besides chemical communication, it is true that most of the studies on OBPs have been associated with chemoreception, while often CSPs have been reported in connection with other physiological events. The exceptional versatility of CSPs might be related to their high capacity of accepting ligands of different sizes. At least in one case, X-ray crystallography has demonstrated that a CSP can swell to a large extent and bind three molecules of 12-Br-dodecanol (Campanacci et al., 2003). The same adaptability is probably the structural reason why CSPs have been adopted in more than one species as scavengers for insecticides of largely different sizes, such as avermectin (Xuan et al., 2014) and thiametoxam (Liu et al., 2014b).

Given such wide repertoire of functions in which CSPs can be involved, it is more difficult to track the use of these proteins in chemodetection across arthropods. To provide a comprehensive picture of CSPs, a phylogenetic tree built on the sequences from selected insect species and all those found so far in other arthropods is reported in Figure 4. More detailed data are provided in Table 1.

As a matter of fact, genes encoding CSPs have been found in arthropods other than insects (Pelosi et al., 2006; Zhou et al., 2006), but it would be hard to state that these proteins take the place of OBPs in those species. In fact, no more than one or two sequences have been detected in each species, even when, as in the case of Daphnia pulex, full genomic information is available. It would be more reasonable to link the presence of these CSPs to other functions, such as development. This view is also suggested by the fact that all CSPs of basal hexapods and non-insect arthropods, with the only exception of the single sequence of I. scapularis, cluster in the same large group, together with CSP5 of the honeybee, a protein only found in ovaries and eggs and shown, using experiments of RNA interference, to be required for a correct development of the embryo (Maleszka et al., 2007). Another few insect CSPs, of so far unknown functions, are found in the same branch of the tree; it would be tempting to speculate that perhaps they could also be involved in development or other roles. On the other hand, the single CSP of I. scapularis, so far identified, clusters with three members of the mosquito A. gambiae (SAP1SAP3) specifically expressed in antennae (Mastrobuoni et al., 2013) and reported to bind several odorants (Iovinella et al., 2013).

Taken together, the information available so far suggests that a role of CSPs in chemodetection, similar to that reported for OBPs, can only be recognized in insects.

Therefore, while insects make use of both OBPs and CSPs in chemical communication, we are left with no candidates for analogous roles in other arthropods.

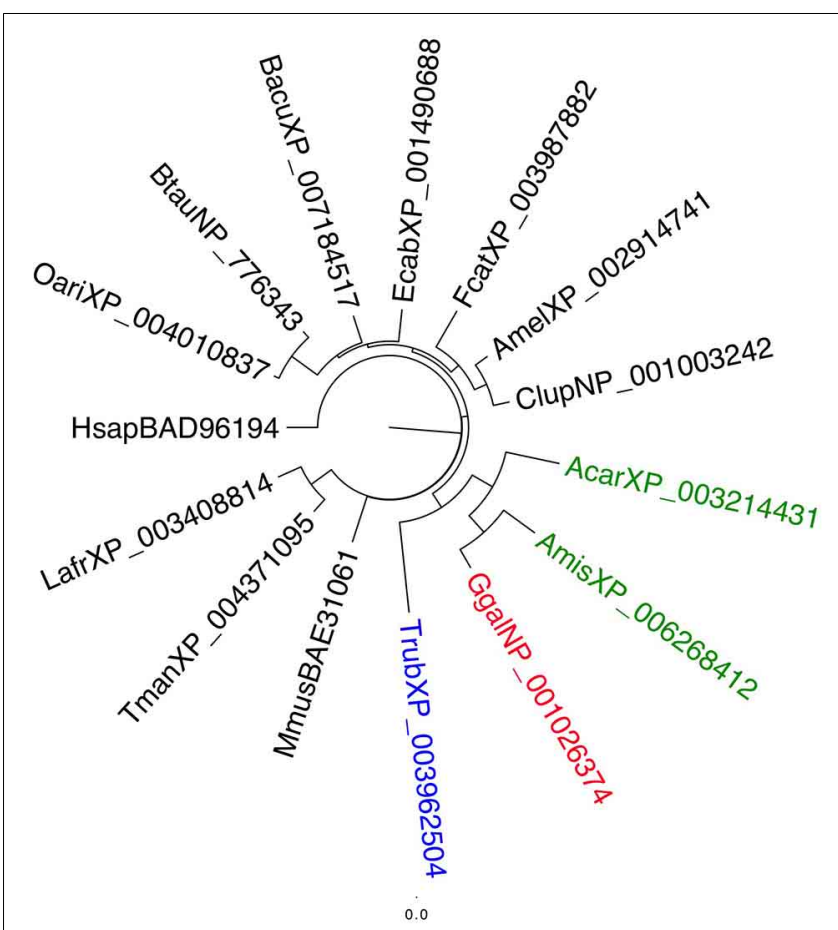

FIGURE 5 | Phylogenetic tree of NPC2 proteins from selected species of vertebrates. These proteins are highly conserved in vertebrates and only a single gene is present in each species. Their role is to bind and transport cholesterol and other lipids. Species and color codes are as follows. Green: Reptiles (Acar: Anolis carolinensis; Amis: Alligator mississippiensis); blue: Fishes (Trub: Takifugu rubripes); red: Birds (Ggal: Gallus gallus); black: Mammals (Mmus: Mus musculus; Fcat: Felis catus; Clup: Canis lupus; Btau: Bos taurus; Ecab: Equus caballus; Oari: Ovis aries; Amel: Ailuropoda melanoleuca; Lafr: Loxodonta africana; Bacu: Balaenoptera acutorostrata; Tman: Trichechus manatus; Hsap: Homo sapiens). Sequences were aligned and trees were visualized as in Figure 2. Names of sequences include accession numbers. 


\section{A NEW PUTATIVE CLASS OF TRANSPORT PROTEINS FOR SEMIOCHEMICALS}

To identify suitable candidate proteins in other arthropods which might perform the roles of OBPs and CSPS in Hexapoda chemical communication, we searched among the available databases for other families of binding proteins using the following criteria and guidelines: (a) there should be a sufficient number of genes in the same species (probably at least a dozen, taking as a reference the 12 OBPs of some ant species), to ensure recognition of complex chemical stimuli using a "combinatorial code" (Malnic et al., 1999);

(b) similarly to OBPs and CSPs, these proteins should be small and soluble;

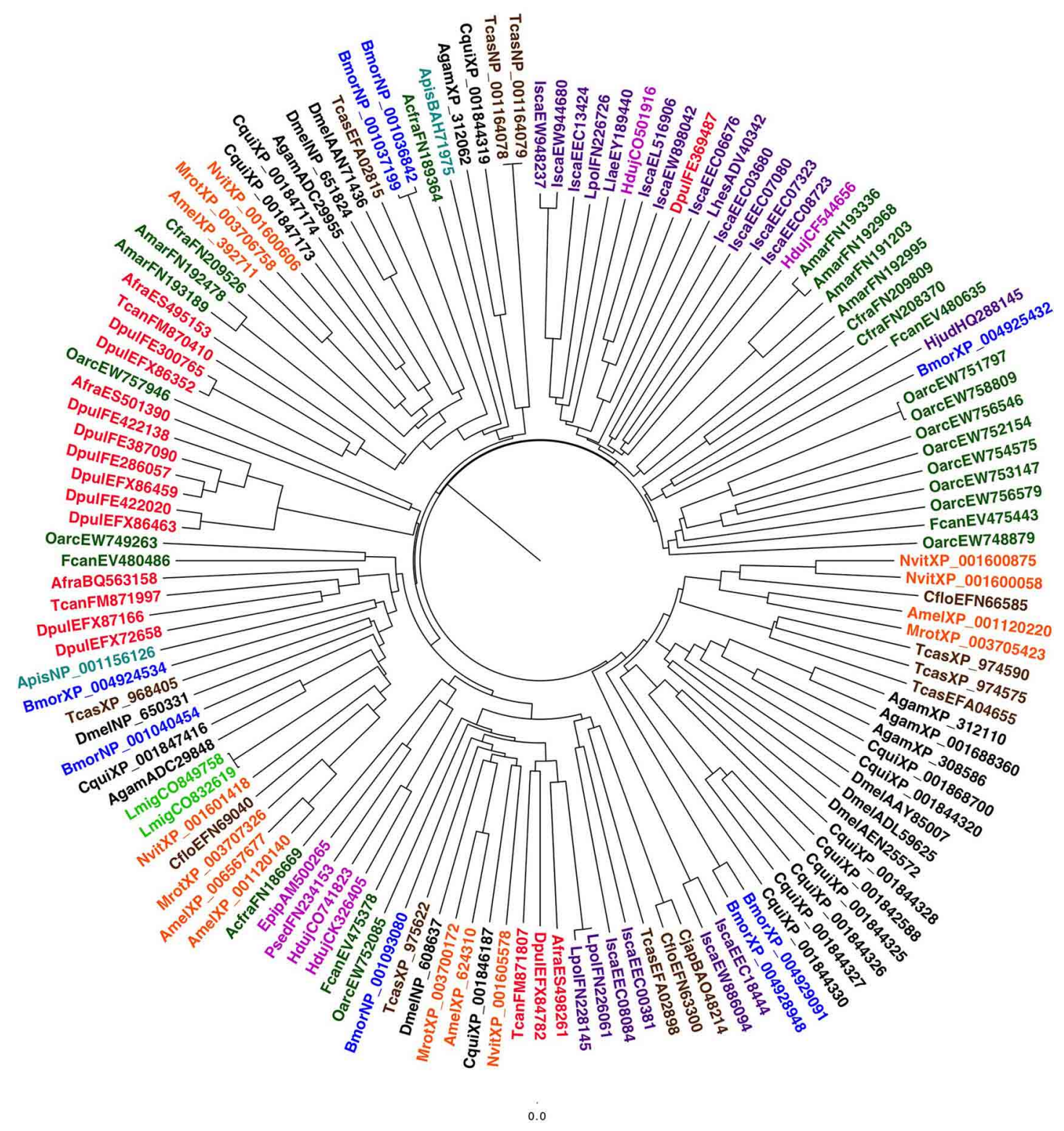

FIGURE 6 | Similarity tree of Npc2s from selected species of insects and other arthropods. Phylogenetic tree of NPC2 proteins from selected species of insects and other arthropods, as well as "sister groups." Species and color codes are as follows: magenta: Tardigrada (Hduj: Hypsibius dujardini) and Onychophora (Psed: Peripatopsis sedgwicki; Epip: Epiperipatus sp.); violet: Euchelicerata (Lpol: Limulus polyphemus; Lhesp: Latrodectus hesperus; Llae: Loxosceles laeta; Hjud: Hottentotta judaicus; Isca: Ixodes scapularis); red: Crustacea (Afra: Artemia franciscana; Dpul: Daphnia pulex; Tcan: Triops cancriformis); green: Collembola (Acfra: Acerentomon franzi; Fcan: Folsomia candida; Amar: Anurida maritima; Oarc: Onychiurus arcticus); light green: Orthoptera (Lmig: Locusta migratoria); light blue: Hemiptera (Apis: Acyrthosiphon pisum); brown: Coleoptera (Tcas: Tribolium castaneum; Cjap: Camponotus japonicus; Cflo: Camponotus floridanus); blue: Lepidoptera (Bmor: Bombyx mori); orange: Hymenoptera (Amel: Apis mellifera; Mrot: Megachile rotundata; Nvit: Nasonia vitripennis); black: Diptera (Dmel: Drosophila melanogaster, Cqui: Culex quinquefasciatus; Agam: Anopheles gambiae). Sequences were aligned and trees were visualized as in Figure 2. Names of sequences include accession numbers. 
(c) their structure should include a hydrophobic binding pocket;

(d) being in contact with the external environment, they should be extremely stable to temperature, chemical agents and proteolysis, as much as OBPs and CSPs are.

This last characteristic brings an important consequence which greatly helped our search: small stable proteins are often powerful allergens, as they can reach the blood stream unchanged or slightly affected and trigger immune responses. It is wellknown that most lipocalins are allergens, the best examples being $\beta$-lactoglobulin (Mäntyjärvi et al., 2000) and several mammalian OBPs, such as Equ-c1, highly abundant in horse sweat (D'Innocenzo et al., 2006). In fact, quite a number of proteins, first reported as allergens, turned out to be members of the mammalian OBP family.

Based on these considerations, we searched for families of allergens presenting a small size and compact structure. We first analyzed the genome of the tick I. scapularis and found 14 sequences classified as Nieman-Pick proteins, type C2 (NPC2), which could fulfill our criteria.

\section{NPC2 IN VERTEBRATES}

This family of proteins has been widely studied in vertebrates, where they are associated with cholesterol and lipid binding and trafficking (Storch and Xu, 2009). A search through the databases has returned only a single sequence per species of mammals and other vertebrates. Figure 5 reports a phylogenetic tree of NPC2 from representative vertebrates. Another characteristic of NPC2 of vertebrates is their high conservation across species, with identity values higher than $75 \%$ between mammalians and around $55-70 \%$ between mammals and other vertebrates. This is hardly surprising if their function is the same in all species, mainly to bind cholesterol and lipids.

\section{NPC2 IN ARTHROPODS}

During the course of our search, a paper reporting the expression of a member of the NPC2 family in the antennae of the ant Camponotus japonicus (Ishida et al., 2014), supported our hypothesis that such proteins could be involved in chemodetection.

Our analysis through the databases of arthropod proteins and genes, using as a template both our previously found 14 sequences of I. scapularis, as well as that of C. japonicus, returned few genes for each species. Figure 6 reports a phylogenetic tree of the NPC2 sequences found in representative insect species and all of those so far found in other arthropods, including the sister groups Tardigrada and Onychophora. We can observe that the number of these proteins in each species of insects is variable, between 2 and 13 in the species where genome information is available. To verify whether these genes were actually expressed at the protein level, we searched through the results of our previous proteome projects (Dani et al., 2011; Iovinella et al., 2011; Mastrobuoni et al., 2013; Zhou et al., 2013), as well as those published by other groups (Chan et al., 2006, 2011, 2013; Sirot et al., 2008; Baer et al., 2009; Swarup et al., 2011). We found that four of the five genes of A. mellifera are expressed at the protein level, but only two in the antennae (acc. no. XP_624310; XP_001120140). The products of all these four genes have been detected in several different tissues and organs from individuals of queens, drones and workers, most of them not involved in chemical communication. Moreover, we

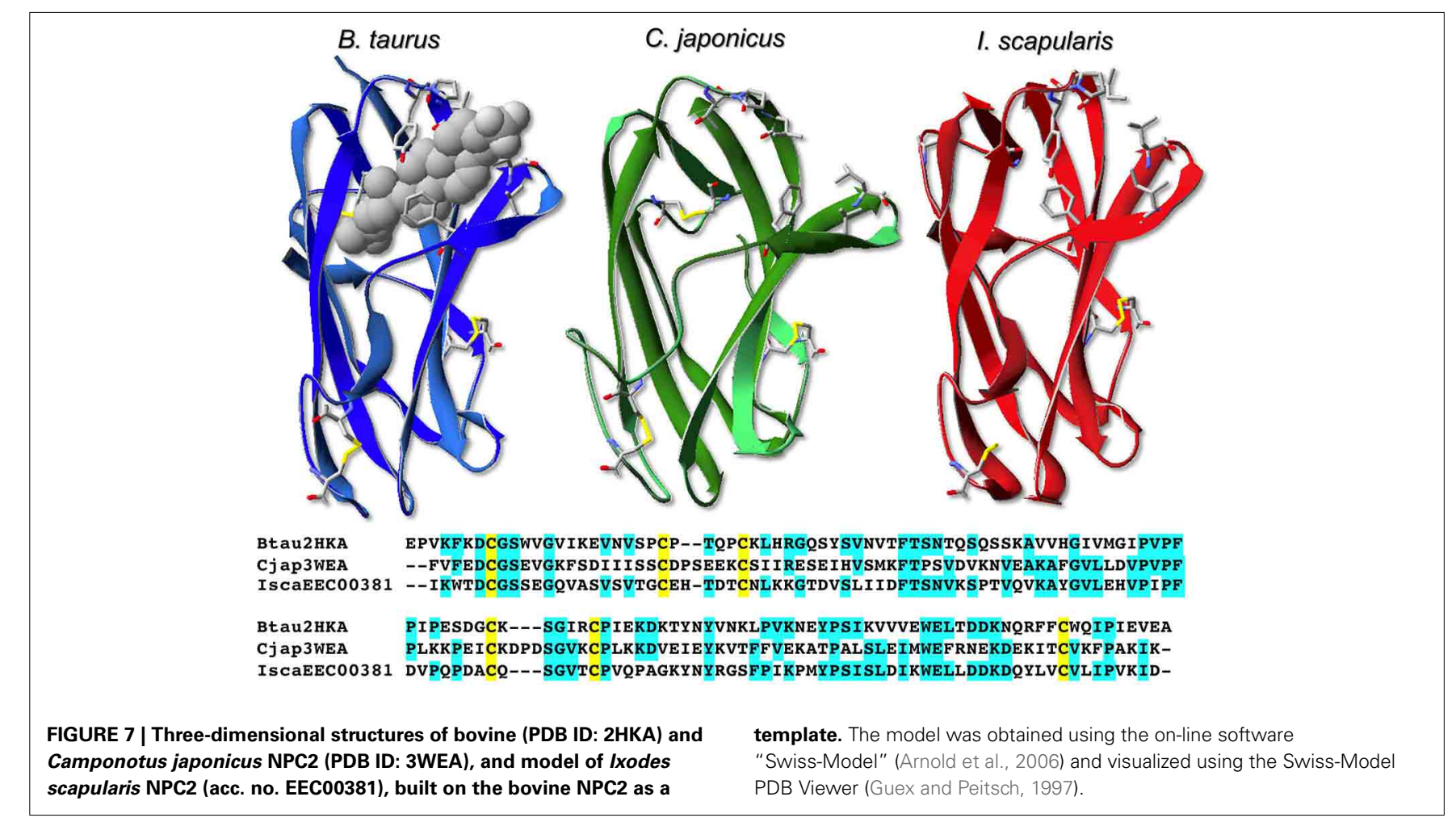


could not find any of the NPC2 proteins in the antennae nor in other examined tissues of B. mori, A. gambiae, L. migratoria, A. aegypti, and D. melanogaster, as far as reported in the above cited papers.

In other arthropods, apart from the 14 sequences of I. scapularis we found 12 genes encoding NPC2 proteins in Daphnia pulex and 11 in the collembolan Onychiurus arcticus, besides fewer members in other basal hexapods (Table 1). Orthologs of these proteins also are present in related species, such as I. ricinus, D. magna and others, but for better clarity we prefer to limit the number of sequences reported in Figure 6 and Table 1 to those of selected species. We also identified 4 sequences in the tardigradan species Hypsibius dujardini, 3 in Limulus polyphemus (Xiphosura) and one in each of two species of Onychophora, Peripatopsis sedgwicki and Epiparipatus $\mathrm{sp}$. As these data are based on very limited sequence information for all these species (except for I. scapularis and D. pulex, whose genome projects have been published), the actual number of NPC2 expressed in each of them could reasonably be higher.

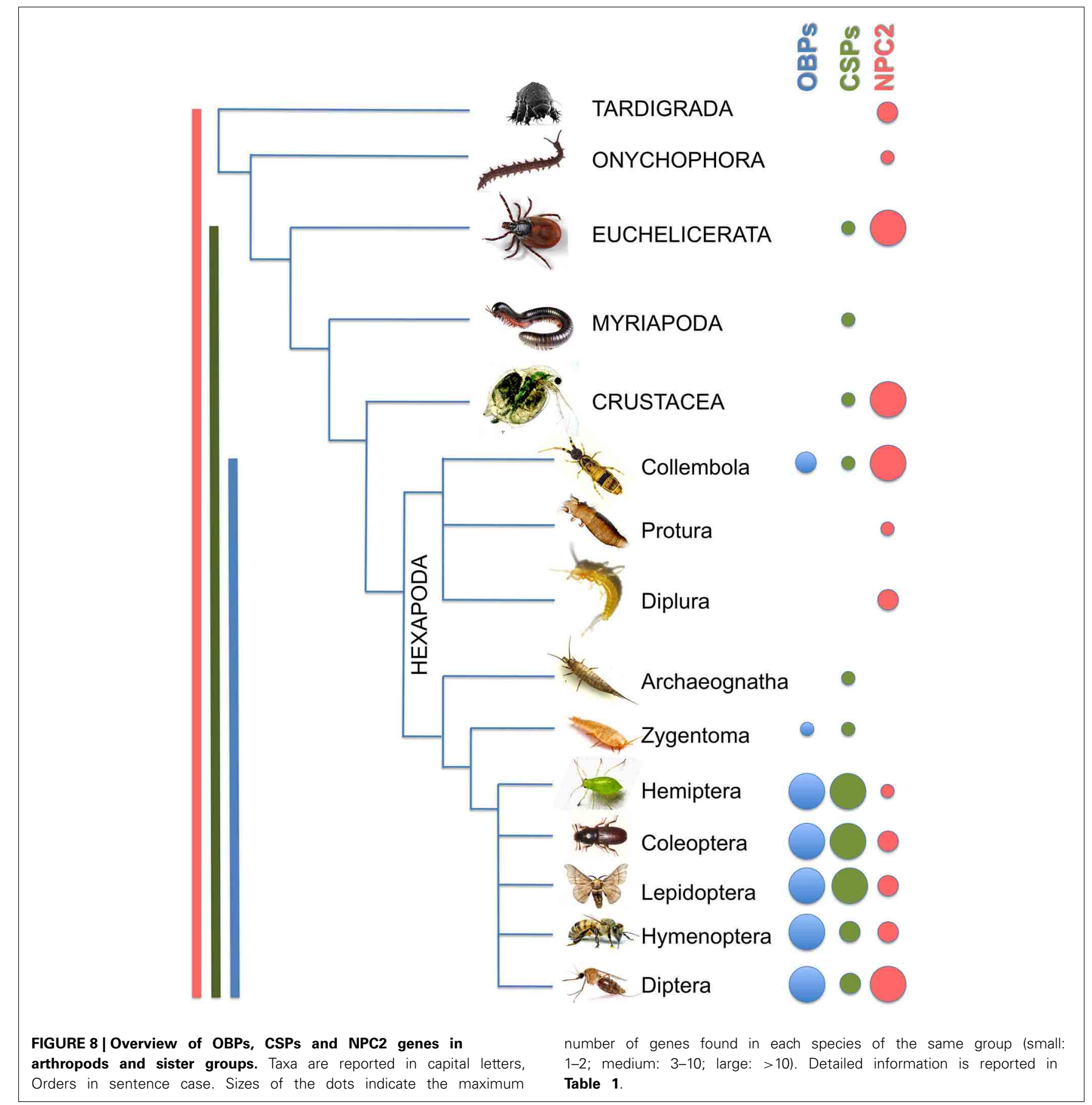




\section{THREE-DIMENSIONAL STRUCTURE OF NPC2}

The folding of several NPC2 proteins of vertebrate has been solved. It is a very compact and conserved structure resembling a sort of cylindrical basket made of $\beta$-sheets and enclosing the binding cavity for cholesterol and other lipids (Figure 7). It reminds in some way of the $\beta$-barrel motif of vertebrate OBPs and more in general of lipocalins. Curiously, NPC2 proteins present a conserved motif of six cysteines paired in three disulfide bridges, similarly to insect OBPs, although this might be no more than a coincidence. Figure 7 also reports a model of one of $I$. scapularis proteins, built on the structure of the bovine member (PDB ID: 2HKA), together with the structure of C. japonicus NPC2 (PDB ID: 3WEA, Ishida et al., 2014). The entrance to the cavity is gated by a number of amino acids (V59, V64, F66, Y100, P101, I103) conserved or replaced by very similar residues in most of the 14 sequences of I. scapularis. These residues are shown in Figure 7. The binding pocket in the model of the tick protein, as in the structure of the bovine one, is lined with a large number of hydrophobic residues.

\section{CONCLUDING REMARKS}

In our analysis of soluble proteins likely to be involved in chemical communication across evolution, as summarized in Figure 8, we have found that:

1. OBPs are present in all species of insects so far investigated, including the most primitive ones, but are completely absent in non-insect arthropods.

2. CSPs are more widely expressed and seem to have appeared earlier than OBPs during evolution. In fact, apart from insects, members of this family have been reported in Crustacea, Myriapoda, and Euchelicerata. However, in these groups the small number of genes in each species does not seem to support a function in chemoreception and other roles could be performed by CSPs in non-insect arthropods.

3. We propose that in non-insect arthropods proteins of the NPC2 family might fulfill the role of semiochemical carrier performed by OBPs and CSPs in insects. These proteins are small, soluble and secreted. They present a compact folding resembling under certain aspects the $\beta$-barrel of vertebrate OBPs with a binding pocket lined by hydrophobic residues.

4. The relatively large number of NPC2 proteins found in some arthropods and their wide differentiation within the same species suggest that they may have evolved to play a function in binding and discrimination of a variety of semiochemicals.

Certainly the account of soluble proteins of chemoreception in arthropods we have presented in this summary is still fragmentary and incomplete. The fast developing techniques of genome and trascriptome sequencing, as well as proteomic tools, will provide in the near future the necessary information to fill all the gaps and contribute to complete the complex picture of different soluble proteins in chemical communication.

\section{SUPPLEMENTARY MATERIAL}

The Supplementary Material for this article can be found online at: http://journal.frontiersin.org/journal/10.3389/fphys. 2014.00320/abstract

\section{REFERENCES}

Angeli, S., Ceron, F., Scaloni, A., Monti, M., Monteforti, G., Minnocci, A., et al. (1999). Purification, structural characterization, cloning and immunocytochemical localization of chemoreception proteins from Schistocerca gregaria. Eur. J. Biochem. 262, 745-754. doi: 10.1046/j.1432-1327.1999.00438.x

Arnold, K., Bordoli, L., Kopp, J., and Schwede, T. (2006). The SWISS-MODEL Workspace: a web-based environment for protein structure homology modelling. Bioinformatics 22, 195-201. doi: 10.1093/bioinformatics/bti770

Bacchini, A., Gaetani, E., and Cavaggioni, A. (1992). Pheromone-binding proteins in the mouse Mus musculus. Experientia 48, 419-421. doi: 10.1007/BF01923448

Baer, B., Heazlewood, J. L., Taylor, N. L., Eubel, H., and Millar, A. H. (2009). The seminal fluid proteome of the honeybee Apis mellifera. Proteomics 9, 2085-2097. doi: 10.1002/pmic.200800708

Ban, L., Napolitano, E., Serra, A., Zhou, X., Iovinella, I., and Pelosi, P. (2013). Identification of pheromone-like compounds in male reproductive organs of the oriental locust Locusta migratoria. Biochem. Biophys. Res. Commun. 437, 620-624. doi: 10.1016/j.bbrc.2013.07.015

Ban, L. P., Zhang, L., Yan, Y. H., and Pelosi, P. (2002). Binding properties of a locust's chemosensory protein. Biochem. Biophys. Res. Commun. 293, 50-54. doi: 10.1016/S0006-291X(02)00185-7

Bianchet, M. A., Bains, G., Pelosi, P., Pevsner, J., Snyder, S. H., Monaco, H. L., et al. (1996). The three dimensional structure of bovine odorant-binding protein and its mechanism of odor recognition. Nat. Struct. Biol. 3, 934-939. doi: 10.1038/nsb1196-934

Bignetti, E., Cavaggioni, A., Pelosi, P., Persaud, K. C., Sorbi, R. T., and Tirindelli, R. (1985). Purification and characterization of an odorant binding protein from cow nasal tissue. Eur. J. Biochem. 149, 227-231. doi: 10.1111/j.14321033.1985.tb08916.x

Buck, L., and Axel, R. (1991). A novel multigene family may encode odorant receptors: a molecular basis for odor recognition. Cell 65, 175-187. doi: 10.1016/0092-8674(91)90418-X

Calvello, M., Guerra, N., Brandazza, A., D’Ambrosio, C., Scaloni, A., Dani, F. R. et al. (2003). Soluble proteins of chemical communication in the social wasp Polistes dominulus. Cell. Mol. Life Sci. 60, 1933-1943. doi: 10.1007/s00018-0033186-5

Calvo, E., Mans, B. J., Ribeiro, J. M. C., and Andersen, J. F. (2009). Multifunctionality and mechanism of ligand binding in a mosquito antiinflammatory protein. Proc. Natl. Acad. Sci. U.S.A. 106, 3728-3733. doi: 10.1073/pnas.0813190106

Campanacci, V., Lartigue, A., Hallberg, B. M., Jones, T. A., Giudici-Orticoni, M. T., Tegoni, M., et al. (2003). Moth chemosensory protein exhibits drastic conformational changes and cooperativity on ligand binding. Proc. Natl. Acad. Sci. U.S.A. 29, 5069-5074. doi: 10.1073/pnas.0836654100

Cavaggioni, A., and Mucignat-Caretta, C. (2000). Major urinary proteins, r2u-globulins and aphrodisin. Biochim. Biophys. Acta. 1482, 218-228. doi: 10.1016/S0167-4838(00)00149-7

Cavaggioni, A., Sorbi, R. T., Keen, J. N., Pappin, D. J., and Findlay, J. B. C. (1987). Homology between the pyrazine-binding protein from nasal mucosa and major urinary proteins. FEBS Lett. 212, 225-228. doi: 10.1016/0014-5793(87)81349-2

Chan, Q. W., Chan, M. Y., Logan, M., Fang, Y., Higo, H., and Foster, L. J. (2013) Honeybee protein atlas at organ-level resolution. Genome Res. 23, 1951-1960. doi: $10.1101 /$ gr.155994.113

Chan, Q. W., Howes, C. G., and Foster, L. J. (2006). Quantitative comparison of caste differences in honeybee hemolymph. Mol. Cell. Proteomics 5, 2252-2262. doi: 10.1074/mcp.M600197-MCP200

Chan, Q. W., Mutti, N. S., Foster, L. J., Kocher, S. D., Amdam, G. V., and Wolschin, F. (2011). The worker honeybee fat body proteome is extensively remodeled preceding a major life-history transition. PLOS ONE 6:e24794. doi: 10.1371/journal.pone.0024794

Clyne, P. J., Warr, C. G., Freeman, M. R., Lessing, D., Kim, J., and Carlson, J. R. (1999). A novel family of divergent seven-transmembrane proteins: candidate odorant receptors in Drosophila. Neuron 22, 327-338. doi: 10.1016/S08966273(00)81093-4 
Costa-da-Silva, A. L., Kojin, B. B., Marinotti, O., James, A. A., and Capurro, M. L. (2013). Expression and accumulation of the two-domain odorant-binding protein AaegOBP45 in the ovaries of blood-fed Aedes aegypti. Parasit \& Vectors 6:364. doi: 10.1186/1756-3305-6-364

Dani, F. R., Michelucci, E., Francese, S., Mastrobuoni, G., Cappellozza, S., La Marca, G., et al. (2011). Odorant-binding proteins and Chemosensory proteins in pheromone detection and release in the silkmoth Bombyx mori. Chem. Senses 36, 335-344. doi: 10.1093/chemse/bjq137

Dinh, B. L., Tremblay, A., and Dufour, D. (1965). Immunochemical study on rat urinary proteins: their relation to serum and kidney proteins (chromatographic separation of the major urinary protein). J. Immunol. 95, 574-582.

D’Innocenzo, B., Salzano, A. M., D’Ambrosio, C., Gazzano, A., Niccolini, A., Sorce, C., et al. (2006). Secretory proteins as potential semiochemical carriers in the horse. Biochemistry 45, 13418-13428. doi: 10.1021/bi061409p

Finlayson, J. S., Asofsky, R., Potter, M., and Runner, C. C. (1965). Major urinary protein complex of normal mice: origin. Science 149, 981-982. doi: 10.1126/science.149.3687.981

Flower, D. R. (1996). The lipocalin protein family: structure and function. Biochem. J. 318, 1-14.

Flower, D. R. (2000). Experimentally determined lipocalin structures. Biochim. Biophys. Acta 1482, 46-56. doi: 10.1016/S0167-4838(00)00147-3

Flower, D. R., North, A. C., and Sansom, C. E. (2000). The lipocalin protein family: structural and sequence overview. Biochim. Biophys. Acta 1482, 9-24. doi: 10.1016/S0167-4838(00)00148-5

Forêt, S., Wanner, K. W., and Maleszka, R. (2007). Chemosensory proteins in the honey bee: Insights from the annotated genome, comparative analyses and expressional profiling. Insect Biochem. Mol. Biol. 37, 19-28. doi: 10.1016/j.ibmb.2006.09.009

Giribet, G., and Edgecombe, G. D. (2012). Reevaluating the Arthropod tree of life. Annu. Rev. Entomol. 57, 167-186. doi: 10.1146/annurev-ento-120710-100659

Giribet, G., Edgecombe, G. D., Carpenter, J. M., D’Haese, C. A., and Wheeler, W. C. (2004). Is Ellipura monophyletic? A combined analysis of basal hexapod relationships with emphasis on the origin of insects. Org. Divers. Evol. 4, 319-340. doi: 10.1016/j.ode.2004.05.001

Gu, S.-H., Wu, K.-M., Guo, Y.-Y., Pickett, J. A., Field, L. M., Zhou, J.-J., et al. (2013). Identification of genes expressed in the sex pheromone gland of the black cutworm Agrotis ipsilon with putative roles in sex pheromone biosynthesis and transport. BMC Genomics 14:636. doi: 10.1186/1471-2164-14-636

Guex, N., and Peitsch, M. C. (1997). SWISS-MODEL and the Swiss-PdbViewer: An environment for comparative protein modeling. Electrophoresis 18, 2714-2723. doi: 10.1002/elps.1150181505

Iovinella, I., Bozza, F., Caputo, B., Della Torre, A., and Pelosi, P. (2013). Ligandbinding study of Anopheles gambiae chemosensory proteins. Chem. Senses 38, 409-419. doi: 10.1093/chemse/bjt012

Iovinella, I., Dani, F. R., Niccolini, A., Sagona, S., Michelucci, E., Gazzano, A., et al. (2011). Differential expression of odorant-binding proteins in the mandibular glands of the honey bee according to caste and age. J. Proteome Res. 10, 3439-3449. doi: 10.1021/pr2000754

Ishida, Y., Ishibashi, J., and Leal, W. S. (2013). Fatty acid solubilizer from the oral disk of the blowfly. PLoS ONE 8:e51779. doi: 10.1371/journal.pone.0051779

Ishida, Y., Tsuchiya, W., Fujii, T., Fujimoto, Z., Miyazawa, M., Ishibashi, J., et al. (2014). Niemann-Pick type C2 protein mediating chemical communication in the worker ant. Proc. Natl. Acad. Sci. U.S.A. 111, 3847-3852. doi: $10.1073 /$ pnas.1323928111

Jacquin-Joly, E., Vogt, R. G., François, M. C., and Nagnan-Le Meillour, P. (2001). Functional and expression pattern analysis of chemosensory proteins expressed in antennae and pheromonal gland of Mamestra brassicae. Chem. Senses 26, 833-844. doi: 10.1093/chemse/26.7.833

Jansen, S., Chmelík, J., Zídek, L., Padrta, P., Novák, P., Zdráhal, Z., et al. (2007). Structure of Bombyx mori chemosensory protein 1 in solution. Arch. Insect. Biochem. Physiol. 66, 135-145. doi: 10.1002/arch.20205

Kitabayashi, A. N., Arai, T., Kubo, T., and Natori, S. (1998). Molecular cloning of cDNA for p10, a novel protein that increases in the regenerating legs of Periplaneta americana (American cockroach). Insect Biochem. Mol. Biol. 28, 785-790. doi: 10.1016/S0965-1748(98) 00058-7

Lartigue, A., Campanacci, V., Roussel, A., Larsson, A. M., Jones, T. A., Tegoni, M., et al. (2002). X-ray structure and ligand binding study of a moth chemosensory protein. J. Biol. Chem. 277, 32094-32098. doi: 10.1074/jbc.M204371200
Laughlin, J. D., Ha, T. S., Jones, D. N. M., and Smith, D. P. (2008). Activation of pheromone-sensitive neurons is mediated by conformational activation of pheromone-binding protein. Cell 133, 1255-1265. doi: 10.1016/j.cell.2008.04.046

Leal, W. (2013). Odorant reception in insects: roles of receptors, binding proteins, and degrading enzymes. Annu. Rev. Entomol. 58, 373-391. doi: 10.1146/annurev-ento-120811-153635

Leal, W. S., Nikonova, L., and Peng, G. (1999). Disulfide structure of the pheromone binding protein from the silkworm moth, Bombyx mori. FEBS Lett. 464, 85-90. doi: 10.1016/S0014-5793(99)01683-X

Li, S., Picimbon, J. F., Ji, S. D., Kan, Y. C., Qiao, C. L., Zhou, J. J., et al. (2008). Multiple functions of an odorant-binding protein in the mosquito Aedes aegypti. Biochem. Biophys. Res. Comm. 372, 464-468. doi: 10.1016/j.bbrc.2008.05.064

Liu, G. X., Xuan, N., Chu, D., Xie, H. Y., Fan, Z. X., Bi, Y. P., et al. (2014b). Biotype expression and insecticide response of Bemisia tabaci chemosensory protein-1. Arch. Insect Biochem. Physiol. 85, 137-151. doi: 10.1002/arch.21148

Liu, Y. L., Guo, H., Huang, L. Q., Pelosi, P., and Wang, C. Z. (2014a). Unique function of a chemosensory protein in the proboscis of two Helicoverpa species. J. Exp. Biol. 217, 1821-1826. doi: 10.1242/jeb.102020

Loebel, D., Scaloni, A., Paolini, S., Fini, C., Ferrara, L., Breer, H., et al. (2000) Cloning, post-translational modifications, heterologous expression and ligandbinding of boar salivary lipocalin. Biochem. J. 350, 369-379. doi: 10.1042/02646021:3500369

Maleszka, J., Forêt, S., Saint, R., and Maleszka, R. (2007). RNAi-induced phenotypes suggest a novel role for a chemosensory protein CSP5 in the development of embryonic integument in the honeybee (Apis mellifera). Dev. Genes Evol. 217, 189-196. doi: 10.1007/s00427-006-0127-y

Malnic, B., Hirono, J., Sato, T., and Buck, L. B. (1999). Combinatorial receptor codes for odors. Cell 96, 713-723. doi: 10.1016/S0092-8674(00)80581-4

Manoharan, M., Ng Fuk Chong, M., Vaïtinadapoulé, A., Frumence, E., Sowdhamini, R., and Offmann, B. (2013). Comparative genomics of odorant binding proteins in Anopheles gambiae, Aedes aegypti and Culex quinquefasciatus. Genome Biol. Evol. 5, 163-180. doi: 10.1093/gbe/evs131

Mäntyjärvi, R., Rautiainen, J., and Virtanen, T. (2000). Lipocalins as allergens. Biochim. Biophys. Acta 1482, 308-317. doi: 10.1016/S0167-4838(00)00139-4

Marchese, S., Pes, D., Scaloni, A., Carbone, V., and Pelosi, P. (1998). Lipocalins of boar salivary glands binding odours and pheromones. Eur. J. Biochem. 252, 563-568. doi: 10.1046/j.1432-1327.1998.2520563.x

Marinotti, O., Ngo, T., Kojin, B. B., Chou, S. P., Nguyen, B., Juhn, J., et al. (2014). Integrated proteomic and transcriptomic analysis of the Aedes aegypti eggshell. BMC Dev. Biol. 14:15. doi: 10.1186/1471-213X-14-15

Mastrobuoni, G., Qiao, H., Iovinella, I., Sagona, S., Niccolini, A., Boscaro, F., et al. (2013). A proteomic investigation of soluble olfactory proteins in Anopheles gambiae. PLoS ONE 8:e75162. doi: 10.1371/journal.pone.0075162

Mastrogiacomo, R., D’Ambrosio, C., Niccolini, A., Serra, A., Gazzano, A., Scaloni, A., et al. (2014). An odorant-binding protein is abundantly expressed in the nose and in the seminal fluid of the rabbit. Plos ONE. (in press).

Matsuo, T., Sugaya, S., Yasukawa, J., Aigaki, T., and Fuyama, Y. (2007). Odorantbinding proteins OBP57d and OBP57e affect taste perception and hostplant preference in Drosophila sechellia. PLoS Biol. 5:e118. doi: 10.1371/journal.pbio.0050118

McKenna, M. P., Hekmat-Scafe, D. S., Gaines, P., and Carlson, J. R. (1994). Putative Drosophila pheromone-binding proteins expressed in a subregion of the olfactory system. J. Biol. Chem. 269, 16340-16347.

Nomura, A., Kawasaki, K., Kubo, T., and Natori, S. (1992). Purification and localization of $\mathrm{p} 10$, a novel protein that increases in nymphal regenerating legs of Periplaneta americana American cockroach. Int. J. Dev. Biol. 36, 391-398.

Paolini, S., Tanfani, F., Fini, C., Bertoli, E., and Pelosi, P. (1999). Porcine odorant-binding protein: structural stability and ligand affinities measured by fourier-transform infrared spectroscopy and fluorescence spectroscopy. Biochim. Biophys. Acta 1431, 179-188. doi: 10.1016/S0167-4838(99)00037-0

Pelosi, P. (1994). Odorant-binding proteins. Crit. Rev. Biochem. Mol. Biol. 29, 199-228. doi: 10.3109/10409239409086801

Pelosi, P. (1996). Perireceptor events in olfaction. J. Neurobiol. 30, 3-19.

Pelosi, P., Baldaccini, N. E., and Pisanelli, A. M. (1982). Identification of a specific olfactory receptor for 2-isobutyl-3-methoxypyrazine. Biochem. J. 201, 245-248.

Pelosi, P., and Maida, R. (1990). Odorant binding proteins in vertebrates and insects: similarities and possible common function. Chem. Senses 15, 205-215. doi: $10.1093 /$ chemse/15.2.205 
Pelosi, P., Pisanelli, A. M., Baldaccini, N. E., and Gagliardo, A. (1981). Binding of 3H-2-isobutyl-3-methoxypyrazine to cow olfactory mucosa. Chem. Senses 6, 77-85. doi: 10.1093/chemse/6.2.77

Pelosi, P., Zhou, J. J., Ban, L. P., and Calvello, M. (2006). Soluble proteins in insect chemical communication. Cell. Mol. Life Sci. 63, 1658-1676. doi: 10.1007/ s00018-005-5607-0

Pevsner, J., Trifiletti, R. R., Strittmatter, S. M., and Snyder, S. H. (1985). Isolation and characterization of an olfactory receptor protein for odorant pyrazines. Proc. Natl. Acad. Sci. U.S.A. 82, 3050-3054. doi: 10.1073/pnas.82.9.3050

Pikielny, C. W., Hasan, G., Rouyer, F., and Rosbash, H. (1994). Members of a family of Drosophila putative odorant-binding proteins are expressed in different subsets of olfactory hairs. Neuron 12, 35-49. doi: 10.1016/0896-6273(94)90150-3

Qiao, H., Tuccori, E., He, X., Gazzano, A., Field, L., Zhou, J. J., et al. (2009). Discrimination of alarm pheromone $(E)$ - $\beta$-farnesene by aphid odorant-binding proteins. Insect Biochem. Mol. Biol. 39, 414-419. doi: 10.1016/j.ibmb.2009. 03.004

Robertson, D. H., Beynon, R. J., and Evershed, R. P. (1993). Extraction, characterization, and binding analysis of two pheromonally active ligands associated with major urinary protein of house mouse (Mus musculus). J. Chem. Ecol. 19, 1405-1416. doi: 10.1007/BF00984885

Sandler, B. H., Nikonova, L., Leal, W. S., and Clardy, J. (2000). Sexual attraction in the silkworm moth: structure of the pheromone-binding-proteinbombykol complex. Chem. Biol. 7, 143-151. doi: 10.1016/S1074-5521(00) 00078-8

Scaloni, A., Monti, M., Angeli, S., and Pelosi, P. (1999). Structural analyses and disulfide-bridge pairing of two odorant-binding proteins from Bombyx mori. Biochem. Biophys. Res. Commun. 266, 386-391. doi: 10.1006/bbrc. 1999.1791

Schwaighofer, A., Pechlaner, M., Oostenbrink, C., Kotlowski, C., Araman, C., Mastrogiacomo, R., et al. (2014). Insights into structural features determining odorant affinities to honey bee odorant binding protein 14. Biochem. Biophys. Res. Commun. 446, 1042-1046. doi: 10.1016/j.bbrc.2014.03.054

Singer, A. G., Macrides, F., Clancy, A. N., and Agosta, W. C. (1986). Purification and analysis of a proteinaceous aphrodisiac pheromone from hamster vaginal discharge. J Biol. Chem. 261, 13323-13326.

Sirot, L. K., Poulson, R. L., McKenna, M. C., Girnary, H., Wolfner, M. F., and Harrington, L. C. (2008). Identity and transfer of male reproductive gland proteins of the dengue vector mosquito, Aedes aegypti: potential tools for control of female feeding and reproduction. Insect Biochem. Mol. Biol. 38, 176-189. doi: 10.1016/j.ibmb.2007.10.007

Smith, C. D., Zimin, A., Holt, C., Abouheif, E., Benton, R., Cash, E., et al. (2011). Draft genome of the globally widespread and invasive Argentine ant (Linepithema humile). Proc. Natl. Acad. Sci. U.S.A. 108, 5673-5678. doi: 10.1073/pnas. 1008617108

Spinelli, S., Vincent, F., Pelosi, P., Tegoni, M., and Cambillau, C. (2002). Boar salivary lipocalin. Three-dimensional X-ray structure and androsterol/androstenone docking simulations. Eur. J. Biochem. 269, 2449-2456. doi: 10.1046/j.1432-1033.2002.02901.x

Storch, J., and Xu, Z. (2009). Niemann-Pick C2 (NPC2) and intracellular cholesterol trafficking. Biochim. Biophys. Acta 1791, 671-678. doi: 10.1016/j.bbalip.2009.02.001

Sun, Y. F., De Biasio, F., Qiao, H. L., Iovinella, I., Yang, S. X., Ling, Y., et al. (2012a). Two odorant-binding proteins mediate the behavioural response of aphids to the alarm pheromone (E)-B-farnesene and structural analogues. PLoS ONE 7:e32759. doi: 10.1371/journal.pone.0032759

Sun, Y. L., Huang, L. Q., Pelosi, P., and Wang, C. Z. (2012b). Expression in antennae and reproductive organs suggests a dual role of an odorant-binding protein in two sibling Helicoverpa species PLoS ONE 7:e30040. doi: 10.1371/journal.pone. 0030040

Swarup, S., Williams, T. I., and Anholt, R. R. (2011). Functional dissection of Odorant binding protein genes in Drosophila melanogaster. Genes Brain Behav. 10, 648-657. doi: 10.1111/j.1601-183X.2011.00704.X

Tegoni, M., Campanacci, V., and Cambillau, C. (2004). Structural aspects of sexual attraction and chemical communication in insects. Trends Biochem. Sci. 29, 257-264. doi: 10.1016/j.tibs.2004.03.003
Tegoni, M., Pelosi, P., Vincent, F., Spinelli, S., Campanacci, V., Grolli, S., et al. (2000). Mammalian odorant binding proteins. Biochim. Biophys. Acta 1482, 229-240. doi: 10.1016/S0167-4838(00)00167-9

Tegoni, M., Ramoni, R., Bignetti, E., Spinelli, S., and Cambillau, C. (1996). Domain swapping creates a third putative combining site in bovine odorant binding protein dimer. Nat. Struct. Biol. 3, 863-867. doi: 10.1038/nsb1096-863

Tomaselli, S., Crescenzi, O., Sanfelice, D., Ab, E., Wechselberger, R., Angeli, S., et al. (2006). Solution structure of a chemosensory protein from the desert locust Schistocerca gregaria. Biochemistry 45, 10606-10613. doi: 10.1021/bi060998w

Vieira, F. G., and Rozas, J. (2011). Comparative genomics of the odorant-binding and chemosensory protein gene families across the arthropoda: origin and evolutionary history of the chemosensory system. Genome Biol. Evol. 3, 476-490. doi: 10.1093/gbe/evr033

Vincent, F., Löbel, D., Brown, K., Spinelli, S., Grote, P., Breer, H., et al. (2001). Crystal structure of aphrodisin, a sex pheromone from female hamster. J. Mol. Biol. 305, 459-469. doi: 10.1006/jmbi.2000.4241

Vincent, F., Spinelli, S., Ramoni, R., Grolli, S., Pelosi, P., Cambillau, C., et al. (2000). Complexes of porcine odorant binding protein with odorant molecules belonging to different chemical classes. J. Mol. Biol. 300, 127-139. doi: 10.1006/jmbi. 2000.3820

Vogt, R. G., and Riddiford, L. M. (1981). Pheromone binding and inactivation by moth antennae. Nature 293, 161-163. doi: 10.1038/293161a0

Vosshall, L. B., Amrein, H., Morozov, P. S., Rzhetsky, A., and Axel, R. (1999). A spatial map of olfactory receptor expression in the Drosophila antenna. Cell 96, 725-736. doi: 10.1016/S0092-8674(00)80582-6

Wanner, K. W., Willis, L. G., Theilmann, D. A., Isman, M. B., Feng, Q., and Plettner, E. (2004). Analysis of the insect OS-D-like gene family. J. Chem. Ecol. 30, 889-911. doi: 10.1023/B:JOEC.0000028457.51147.d4

Xu, P., Atkinson, R., Jones, D. N., and Smith, D. P. (2005). Drosophila OBP LUSH is required for activity of pheromone-sensitive neurons. Neuron 45, 193-200. doi: 10.1016/j.neuron.2004.12.031

Xuan, N., Guo, X., Xie, H. Y., Lou, Q. N., Lu, X. B., Liu, G. X., et al. (2014). Increased expression of CSP and CYP genes in adult silkworm females exposed to avermectins. Insect Sci. doi: 10.1111/1744-7917.12116. [Epub ahead of print].

Zeng, C., Spielman, A. I., Vowels, B. R., Leyden, J. J., Biemann, K., and Preti, G. (1996). A human axillary odorant is carried by apolipoprotein D. Proc. Natl. Acad. Sci. U.S.A. 93, 6626-6630. doi: 10.1073/pnas.93.13.6626

Zhou, J. J., Huang, W., Zhang, G. A., Pickett, J. A., and Field, L. M. (2004). "Plus-C" odorant-binding protein genes in two Drosophila species and the malaria mosquito Anopheles gambiae. Gene 327, 117-129. doi: 10.1016/j.gene.2003.11.007

Zhou, J.-J., Kan, J., Antoniw, J., Pickett, J. A., and Field, L. M. (2006). Genome and EST analyses and expression of a gene family with putative functions in insect chemoreception. Chem. Senses 31, 453-465. doi: 10.1093/chemse/bjj050

Zhou, X. H., Ban, L. P., Iovinella, I., Zhao, L. J., Gao, Q., Felicioli, A., et al. (2013). Diversity, abundance and sex-specific expression of chemosensory proteins in the reproductive organs of the locust Locusta migratoria manilensis. Biol. Chem. 394, 43-54. doi: 10.1515/hsz-2012-0114

Conflict of Interest Statement: The authors declare that the research was conducted in the absence of any commercial or financial relationships that could be construed as a potential conflict of interest.

Received: 09 July 2014; accepted: 04 August 2014; published online: 27 August 2014. Citation: Pelosi P, Iovinella I, Felicioli A and Dani FR (2014) Soluble proteins of chemical communication: an overview across arthropods. Front. Physiol. 5:320. doi: 10.3389/ fphys.2014.00320

This article was submitted to Integrative Physiology, a section of the journal Frontiers in Physiology.

Copyright (c) 2014 Pelosi, Iovinella, Felicioli and Dani. This is an open-access article distributed under the terms of the Creative Commons Attribution License (CC BY). The use, distribution or reproduction in other forums is permitted, provided the original author(s) or licensor are credited and that the original publication in this journal is cited, in accordance with accepted academic practice. No use, distribution or reproduction is permitted which does not comply with these terms. 